\title{
El interés de las enfermeras por el alma de los pacientes en proceso de morir: asuntos culturales y espirituales ${ }^{1}$
}

Martha Adíela Lopera Betancur²

María Mercedes Arias Valencia ${ }^{3}$

doi:10.11144/Javeriana.ie19-1.iepa

Cómo citar: Lopera Betancourt MA, Arias Valencia MM. El interés de las enfermeras por el alma de los pacientes en proceso de morir: asuntos culturales y espirituales. Investig Enferm. Imagen Desarr. 2017;19(1): 47-63. http://dx.doi.org/10.11144/Javeriana.ie19-1.iepa

1. Articulo original de investigación. Fecha de recepción: 18 de agosto de 2015. Fecha de aprobación: 27 de enero de 2016

2. Enfermera, Ph. D. Profesora Facultad de Enfermeria. Universidad de Antioquia, Medellín, Colombia. Correo electrónico: Lopera9701@gmail.com

3. Enfermera, Ph. D. Profesora Universidad de Antioquia, Medellin, Colombia. Correo electrónico: mercedes.arias@udea.edu.co 


\section{Resumen}

Las concepciones que tienen las enfermeras sobre la muerte moldean su significado, lo que genera una polisemia en torno a esta noción. Objetivo: Explorar los significados que construyen las enfermeras sobre los asuntos culturales y espirituales relacionados con la muerte de los pacientes. Método: Estudio cualitativo con enfoque etnográfico. Se realizaron 23 entrevistas a enfermeras y aproximadamente 100 horas de observación en un hospital en Medellín (Colombia) entre diciembre del 2012 y noviembre de 2013. Resultados: $\mathrm{El}$ interés por el alma se manifestó como una intención de respetar las concepciones del paciente, familiares y sensibilidad hacia los rituales. El proceso de la muerte se enmarca en un choque cultural. Conclusión: las concepciones culturales y religiosas se manifiestan en la práctica de los cuidados al final de la vida. Los rituales buscan dar tranquilidad al paciente y a sus familiares en el tránsito hacia la muerte de la persona y que "descanse en paz". Por esto, los asuntos culturales y religiosos se relacionan con un interés por el alma.

Palabras clave: cultura; atención de enfermería; actitud frente a la muerte; investigación cualitativa

\section{The interest of nurses for the soul of patients going through a dying process: cultural and spiritual matters}

\section{Abstract}

The conceptions that nurses have on death shape their meaning, which generates polysemy around this notion. Method: A qualitative study with ethnographic approach whose objective was to explore the meanings that nurses have on cultural and spiritual issues related to the death of patients. 23 interviews with nurses and about 100 hours of observation were performed in a hospital in Medellin (Colombia) between December 2012 and November 2013. Results: The interest in the soul manifested itself as an intention to respect the views of the patient, family and sensitivity to the rituals. The process of dying is part of a culture shock. Conclusion: cultural and religious conceptions are manifested in the practice of care at the end of life. The rituals seek to reassure the patient and family in the transition to the death of the person and also to help the patient "rest in peace". Therefore, cultural and religious issues relate to an interest in the soul.

Keywords: culture; nursing care; attitude to death; qualitative research 


\section{O interesse das enfermeiras para a alma dos pacientes em processo de morrer: questões culturais e espirituais}

\section{Resumo}

As concepções que as enfermeiras têm sobre a morte ajeitam o seu significado, o que gera polissemia em torno desta noção. Método: Estudo qualitativo com enfoque etnográfico cujo objetivo foi explorar os significados construídos pelas enfermeiras sobre as questões culturais e espirituais relacionadas à morte dos pacientes. Foram realizadas 23 entrevistas a enfermeiras e aproximadamente 100 horas de observação em um hospital de Medellín (Colômbia) entre dezembro de 2012 e novembro de 2013. Resultados: O interesse pela alma manifestou-se como intenção de respeitar as concepções do paciente, familiares e sensibilidade para os rituais. O processo da morte é enquadrado em um choque cultural. Conclusão: as concepções culturais e religiosas manifestam-se na prática dos cuidados no fim da vida. Os rituais visam dar tranquilidade ao paciente e seus familiares na transição para a morte da pessoa e que ele ou ela "descanse em paz". Portanto, as questões culturais e religiosas são relacionadas com um interesse pela alma.

Palavras-chave: cultura; atendimento em enfermagem; atitude em face da morte; pesquisa qualitativa 


\section{Introducción}

En este artículo nos ocupamos de los asuntos culturales, espirituales y religiosos alrededor de la muerte de los pacientes en proceso de fallecer en el hospital. Para Geertz, la religión es una dimensión simbólica de la acción social, en el mismo sentido, considera que "la cultura denota patrones de significado históricamente transmitidos, incorporados en símbolos; por ella las personas comunican, perpetúan y desarrollan su conocimiento y actitudes acerca de la vida" (1).

La cultura tiene un papel importante en el estudio de la muerte, pues como observan Quijada-González y Tomás y Garrido, el significado de la vida y la muerte varian de una cultura a otra (2) cada quien dependiendo del contexto, las experiencias, las creencias y el rol que asume en diferentes momentos de la vida, le da una interpretación diferente a los hechos, por otro lado, "el pensamiento mágico y los rituales, han servido como instrumento para afrontar el dolor e intentar superar un trance difícilmente asimilable como la muerte"(3). Aries (4), sostiene que la actitud ante este suceso cambia no solo con el lugar, sino también, de manera lenta con el tiempo. Uno de estos cambios se relaciona con el escenario donde sucede, pasando del hogar en medio de los suyos, a la soledad de un hospital (5) donde los pacientes están abocados a relacionarse con creencias de diferentes personas del equipo de salud, incluyendo las enfermeras.

Este estudio se desarrolló en el contexto de la cultura colombiana y antioqueña, donde la muerte tiene presencia cotidiana, en un entramado de condiciones complejas, específicamente, por la violencia que vive el país. Gayol y Kessler (5) opinan que "es difícil sostener hoy la pérdida absoluta de referentes religiosos en las circunstancias y ceremonias que rodean la muerte e incluso la enfermedad". por la complejidad de creencias que habitan en una misma sociedad y hasta en un misma persona.

En este orden de ideas, es pertinente la pregunta sobre la muerte en la cultura colombiana, no solo por la necesidad de reconstrucción posterior a los escenarios de violencia (6), en un país que aspira a dejar atrás el conflicto armado, sino también por la necesidad de mejorar el cuidado de enfermería. Adicionalmente porque el Congreso de la República en abril de 2014 dio vía libre a la Ley Consuelo Devis Saavedra (7), que regula los cuidados paliativos para los colombianos, además en abril del 2015 el Ministerio de Salud dio cumplimiento a la Sentencia T-970 de 2014 de la Corte Constitucional, que establece las directrices para la organización y el funcionamiento de un comité Técnico científico interdisciplinario de acompañamiento para garantizar el derecho a morir con dignidad (8), dos acontecimientos que cambian el panorama para los pacientes y profesionales de la salud y que llevan al reto de analizar los significados de la muerte y los cuidados del paciente en proceso de fallecer.

Se buscó explorar el significado que las enfermeras construyen sobre los asuntos culturales, espirituales y religiosos relacionados con el cuidado de los pacientes en proceso de morir para contribuir al autoconocimiento de las enfermeras y minimizar su propia angustia (9). 


\section{Método}

Este estudio se realizó con un enfoque cualitativo, en tanto que se estudian los aspectos subjetivos relativos al carácter cultural que tiene el significado de la muerte. La elección de los participantes se hizo teniendo en cuenta que fueran enfermeras que hubieran cuidado por lo menos una vez a un paciente en proceso de morir. Participaron 23 profesionales de diferentes edades, 19 mujeres y cuatro hombres de diferentes áreas como: hospitalización, urgencias, cuidados intensivos, cirugía, oncología, cuidado del niño y obstetricia. Ocho contaban con especialización o maestría en diferentes áreas, dos de ellos tenían especialización en oncología y cuidado paliativo.

La información se recolectó mediante entrevistas con el fin que las personas expresaran libremente su punto de vista (10) acerca de la muerte de los pacientes y del cuidado que ofrecen a los pacientes y a sus familiares. Se realizó una sesión por participante para un total de 23 entrevistas. No había un cuestionario o lista de preguntas predeterminadas, las preguntas dependian del desarrollo de la entrevista. Los datos se recolectaron hasta lograr la saturación de las categorías y el establecimiento de las relaciones, en términos de Strauss y Corbin (11).

También se usaron herramientas etnográficas (100 horas de observación participante). Se realizó en una institución hospitalaria de cuarto nivel de la ciudad de Medellín en diferentes áreas y diferentes horas, las observaciones se hicieron en sesiones de 15 minutos a 6 horas, anotando todo lo que pudiera ser de interés para cumplir los objetivos. Se llevó un diario de campo donde se registraron notas necesarias para continuar con la búsqueda de información y el análisis.

Los resultados surgen de un proceso de análisis de los datos mediante procedimiento inductivo, se hizo una lectura general y posteriormente se seleccionaron códigos que se cortaron y agruparon para formar categorias y subcategorias. El análisis se hizo manual y paralelo a la obtención de los datos.

Para garantizar el rigor se siguieron las recomendaciones de Castillo y Vásquez (12). Primero se contempló el criterio de credibilidad, para ello se presentaron los resultados a algunos participantes, también fue revisado por enfermeras asistenciales que han cuidado pacientes en proceso de fallecer y por pares académicos, con la intención de buscar explicaciones alternativas para los datos.

Para velar por la auditabilidad y la transferibilidad se detalló la ruta metodológica. Los datos se examinaron como un todo en los resultados, en éstos se describe lo típico de las respuestas de los participantes. El rigor se respetó desde el inicio del proceso de investigación. Durante la investigación se cuidaron aspectos éticos y las disposiciones consignadas en la Resolución 8430 de 1993 para investigaciones de bajo riesgo (13), como el respeto por los participantes, los datos del estudio y la autonomía de participar o no en el estudio (aunque nadie se negó a hacerlo). Para proteger la privacidad y confidencialidad de los participantes, los datos se analizaron de manera global, en el momento de citar algún testimonio se hizo de manera impersonal, usando como seudónimo nombres de personajes de la literatura universal, 
que en ocasiones ellos mismos eligieron. Los datos son exclusivos para este proyecto y se guardarán por 2 años después de publicado. Se realizó consentimiento informado antes de la entrevista y observaciones. Esta investigación recibió el aval del Comité de Ética de la Facultad de Enfermería de la Universidad de Antioquia con acta NO_CEI-FE 2012-3.

\section{Resultados}

El presente artículo trata sobre algunas concepciones culturales y espirituales alrededor de la muerte de los pacientes en nuestra realidad colombiana y del papel de las mismas en el cuidado del paciente en proceso de morir.

Se presenta el siguiente mapa, en el cual se hace explicita la relación de la categoría principal, el interés por el alma, con las subcategorías: asistencia espiritual y cultural, que involucra el papel que las enfermeras le asignan a los rituales, lo mismo que la asistencia espiritual y cultural al paciente en proceso de morir; la segunda menciona algunos rituales que se llevan a cabo en esta etapa; la tercera se refiere a los choques culturales que enfrenta la enfermera; la siguiente subcategoría la conforman las concepciones de las enfermeras y la última, alude a la preocupación de las enfermeras por el microambiente donde sucede la muerte.

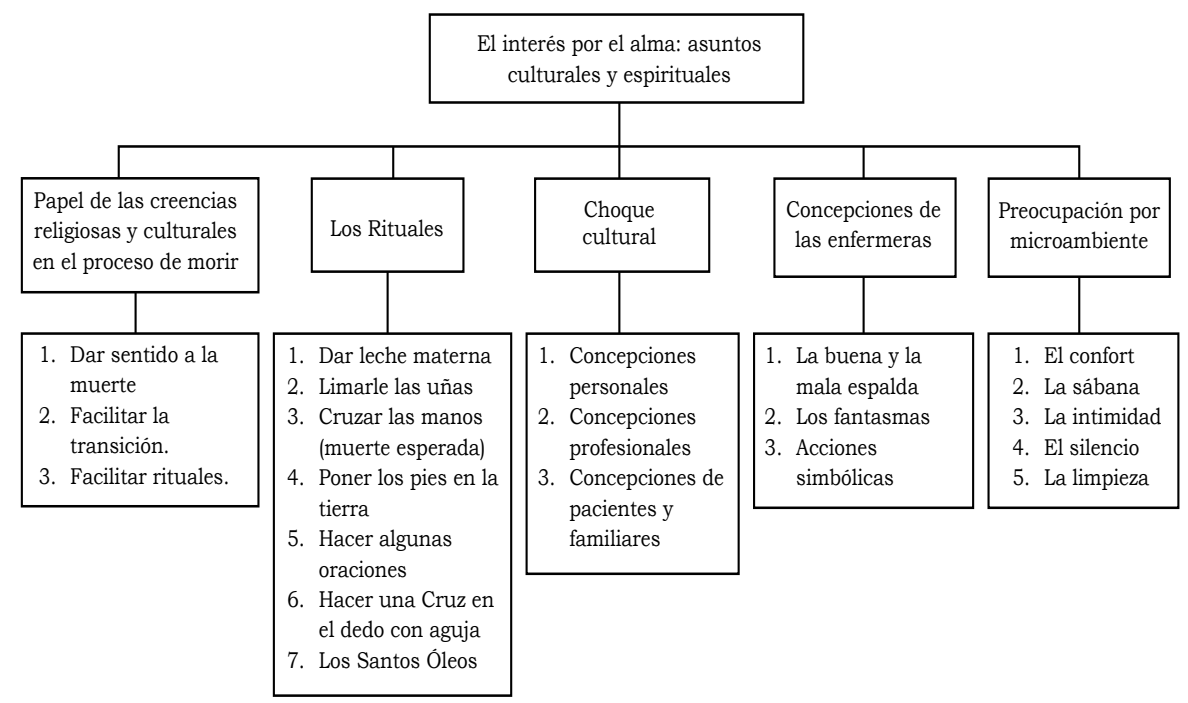

Figura 1. Mapa de relación de categorias con subcategorias

Fuente: Elaboración propia

\section{Papel de las creencias religiosas y culturales en el proceso de morir}


tiempo, dotar de sentido el proceso de dolor y sufrimiento que vive el paciente. Al respecto, dice la participante: "me leí un libro que habla sobre la muerte y lo que más me llamo la atención, es que el cuerpo es el que sufre, ya que debe pagar sus Karmas, creo que como la muerte es tan inexplicable, las personas tienen que sacar diferentes explicaciones para tratar de entender, cierto día un paciente me habló de lo mismo" (Manuela: 2). Un ejemplo se presenta con los pacientes que explican su dolor físico en el "purgar", "expiar" o compensar los errores que cometieron en su vida: "me decía que Dios no es un Dios castigador cuando las personas se mueren, decía que el cuerpo necesitaba sufrir ciertas dolencias para pagar todos los errores cometidos, ya que no habia purgatorio a dónde pagarlos" (Manuela: 2). En el testimonio la enfermera muestra las concepciones religiosas como estrategia que explique su situación: "y desde la religión también le preguntan al Dios de ellos, ¿por qué?” (Celestina: 3). Dichas concepciones buscan dar sentido a la muerte y al dolor y una cierta tranquilidad en el proceso que vive el paciente para que tenga un objetivo y no sea en vano.

También emerge la asistencia espiritual por medio de rituales que buscan que el paciente muera de manera natural o facilitar la transición del mundo de los vivos al de los muertos. Las enfermeras consideran que la agonía larga es un signo de que el paciente no puede morir tranquilo, que está "pegado" o "bloqueado", porque le falta este ritual: "pero es que la hija no lo deja ir tranquilo o lo rezaron, hay otras personas que dicen dele leche materna que eso lo desbloquea y uno ve esas conductas y las mismas familias lo ven" (Joel: 10). Así los rituales buscan la tranquilidad del paciente y el descanso de su alma.

Una forma de asistencia espiritual durante el tránsito hacia la muerte consiste en promover y permitir el acceso a sus rituales y a su figura de apoyo espiritual; como un sacerdote, un pastor o una persona con autoridad entre su comunidad religiosa o cultural., para promover este aspecto as enfermeras preguntan al paciente o a los familiares ¿qué necesitan para morir de manera tranquila?, tal como se aprecia en el siguiente relato: "les pregunto si quieren el sacerdote o si son de otra religión que estén con su guía espiritual[...], dejo que recen una oración" (Julieta: 2). También procuran que la asistencia sea rápida: "el sacerdote, casi todos los pacientes lo piden - que los santos óleos-y se les brinda ese deseo inmediatamente" (Emma: 5). A su vez, el sacerdote constata la petición del paciente o sus familiares y no por iniciativa o imposición de enfermería: "el sacerdote dijo - ¿ellos lo pidieron? - (Observación: 39).

Dicha asistencia espiritual puede darse en forma más activa que oficiar el ritual o ayudar a que los familiares lo hagan. Una enfermera relata su papel activo en un ritual cultural que pidió la familia: "con eso me pasó un evento como charro, ${ }^{4}$ y es que un hijo me dijo que le pusiéramos una cruz en un dedo del pie, que él lo autorizaba, que con eso el paciente se iba a morir- el paciente había sufrido mucho, muchas horas-; como 8 horas

4. Expresión coloquial colombiana, que significa que la situación es graciosa o fuera de lo 
que estábamos esperando que falleciera y el no fallecía y el hijo dijo: - mira él no se va a morir, tienen que hacerle eso, porque si no, no se va a morir, y efectivamente lo hicimos-" (Celestina:11). No hacer o no permitir el ritual trae como consecuencia que se prolongue el sufrimiento. La enfermera oficia el ritual cuando no es posible que otra persona lo haga: "el padre nos entrenó y nos dejó los santos óleos, yo nunca lo hice, siempre me pareció algo muy grande para yo hacerlo [...] pero si es orar" (Dulcinea: 10).

Algunas veces los rituales parten de la iniciativa, ideas y concepciones de la enfermera que los realiza, su religión o cultura puede ayudar al paciente en su proceso de transición a la muerte, estén o no presentes los familiares, como se muestra a continuación:

Esto a veces nace de iniciativa del personal y le dicen a la familia: vea tráigale leche materna y la familia lo hace, con la esperanza que descanse o por lo contrario cuando la familia no lo deja ir, y la familia insiste que él está bien, que está vivo, que él se va a recuperar, y he visto personal que lo hace y dice: voy a limarle las uñas a este paciente, esperando que el paciente se desbloquee y fallezca, pero como iniciativa del personal (Joel: 5).

También lo expresa esta participante: "cuando estaban solos les decía —váyase que usted ya está en paz con Dios - nosotros estamos para que se vayan tranquilos con Dios, que lleguen a la otra vida bien" (Sherazade: 8).

Los rituales: En términos generales, las enfermeras permiten que los pacientes o familiares reciban atención espiritual conforme a sus creencias sin excluir las instituciones donde ellas laboran y la institución donde se realizó el trabajo de campo. El siguiente fragmento da cuenta de un caso paradigmático, en el sentido que la enfermera que dio su testimonio se reconoce como católica y la institución donde labora es una clínica confesional católica. No obstante, relata cómo el personal busca respetar los rituales de los pacientes y los familiares, sin intentar imponer las concepciones de los fundadores, directivos o personal asistencial de la clínica: "me tocó una vez con unos judíos, que pedían estar solo ellos, no podía entrar nadie del área de la salud, en ese momento que había acabado de fallecer, entraron como 50 personas [...] no importa, son 50 personas y ese es su ritual" (Dulcinea: 5). El siguiente caso, también es especial, dado que la enfermera se confiesa como una persona que no tiene un Dios ni religión; sin embargo, dice que respeta que los pacientes y familiares tengan su ritual conforme a su creencia. Además, defiende y promueve el ritual que ellos deseen. En el relato, ella comenta que como enfermera profesional, hace las veces de persona de mayor autoridad en la sala y por esta razón, realiza algunos rituales católicos como bautizar los bebés o aplicarle los santos óleos a las personas de esta religión cuando están en el momento inminente de la muerte; no obstante, dice que prefiere no hacerlo, porque violenta sus propias creencias, dice que lo hace si considera que puede ayudar a los familiares a estar tranquilos: "bueno en 54 neonatos se bautizan, en neonatos uno tiene como un agua que trae el cura y uno la guarda en un armario, y cuando se va a morir un paciente uno se 
la echa" (Celestina: 9). No obstante, se podría entender como una forma de irrespeto hacia una religión que no conoce y en la cual no cree, pues al oficiar un ritual, puede poner en ridículo la creencia delante los familiares y por otra parte, puede ser que el ritual no cumpla el efecto simbólico que se le atribuye de promover la muerte tranquila y brindarle tranquilidad a quien fallece. Para no hacerlo, emplea con el equipo diferentes estrategias intentando dar cumplimiento a la petición del paciente y sus familiares, como lo expresa a continuación: "entonces me pasaba muy charro porque yo no sé rezar, yo no sé nada de eso y me pasó una de las cosas y es que delante de una familia que se estaba muriendo el bebé, una de mis auxiliares me trajo el agua y me dijo - Jefe bautícela - yo no sabía dónde pararme, yo me puse roja y como mi grupo sabía que yo no sabía la religión se vino otra y me salvó y dijo: —venga que yo-y yo le dije: $\mathrm{Si}$, tu rezas muy bonito" (Celestina: 9).

Las enfermeras relatan varios rituales que son iniciativa de los familiares, pero que ellas apoyan: oraciones, dar leche materna al moribundo, hacer una cruz en el dedo, o poner los pies en la tierra, con el fin que la persona que agoniza se entregue a la muerte y se "desprenda", otros por iniciativa de los familiares; como oraciones o cruzar las manos de la persona recién fallecida. Siempre y cuando su muerte no fuera de manera inesperada. Estos buscan que el alma de la persona llegue directo al cielo sin pasar por el purgatorio. A este último caso se refiere la participante: "la verdad de todos los pacientes que mueren, las familias hacen la petición que las manos queden cruzadas, los únicos que no quedan así son los que mueren de manera traumática, por las creencias de ellos, que los ángeles van al cielo y cuando lleguen poderle suplicar a Dios con las manos cruzadas" (Elena: 6).

\section{El cuidado al paciente en proceso de fallecer puede ser un choque cultural.}

Se percibieron nociones en conflicto que pueden entenderse como elementos constitutivos de los choques culturales identificados. El primero se presenta cuando la enfermera expone las concepciones acerca de la muerte que trae desde su familia y su cultura. Estas son poco consultadas por las instituciones formadoras, pero pueden acompañarla durante toda su vida profesional. En el siguiente relato, la enfermera hace explicita su creencia: "somos los ángeles de los pacientes, somos el puente con Dios" (Sherazade: 5). También pueden conservarse algunas expresiones de disgusto o temor a los cadáveres "pero no me gusta verlos ya después de que los tapan, me da como impresión, no sé si eso es miedo o qué” (Ana Karenina: 5).

Otro choque corresponde al momento en que a enfermera llega a una institución hospitalaria con sus concepciones y formación profesional, ella se encuentra con la cultura del hospital, la cual tiene su propia dinámica con respecto a forma de percibir y comportarse ante la muerte de los pacientes y con los moribundos: "—nos reímos del que se muere-, antes me molestaba, porque me parecía que era como agresivo con la persona, pero en realidad 
el que se está muriendo, se está muriendo" (Celestina: 12). Se nota como la enfermera fue tomando de manera natural y acrítica una forma de actuación que tenía el grupo de trabajo al cual se unió; sin embargo, en ocasiones las enfermeras buscan abogar por el derecho que tiene el paciente a morir conforme a su cultura; como se muestra en este testimonio: "y entramos en un conflicto porque yo les dije que por qué lo iban a bautizar, si es que la familia no había dicho que lo bautizaran a ninguna religión, que si ellas sabían a cuál religión lo querian bautizar" (Celestina: 11).

El tercer choque se manifiesta entre las concepciones del paciente y sus familiares con los valores del personal de la institución. El siguiente testimonio relata un caso paradigmático que se presenta en el cuidado de una niña indígena hospitalizada en una unidad de cuidados intensivos neonatales por su condición de bebé pre-término. El choque se presenta porque la enfermera y el equipo de salud hacen juicios ante la conducta de los familiares de la paciente. Ellos interpretan la conducta paterna como falta de interés por la niña, porque era diferente a lo que observaban en otras personas, olvidando el contexto y la explicación cultural de este comportamiento:: "desde el principio decian que la niña era para morir[...] también creo que se volvió como más doloroso, como con rabia, no les importó porque cuando les dijimos que falleció los papás no hicieron ningún tipo de expresión de afecto, ni de dolor, casi como si lo esperaran. Entonces para nosotros fue muy doloroso" (Celestina: 10).

\section{Las concepciones culturales y religiosas de las enfermeras y la práctica de los cuidados.}

Las concepciones se manifiestan en su práctica diaria en forma de acciones de cuidado con contenido cultural. Desde la perspectiva de las enfermeras se procura el bienestar y comodidad al paciente y sus familiares en las horas cercanas a la muerte. Un ejemplo es la aromática ${ }^{5}$ o el café, que está asociado en la cultura colombiana y antioqueña con una bebida que se brinda durante el velorio a las personas que acompañan a los familiares del fallecido, quienes buscan una sensación de tranquilidad en un momento tan doloroso como la muerte.

No se evidenció una petición expresa de los familiares de estas bebidas; sin embargo, fue una acción descrita por los participantes: "les brindo una aromática" (Maya: 5). También es costumbre en la cultura antioqueña brindar una bebida caliente. Probablemente, se asocian estos momentos de duelo a estados fríos.

Por otro lado, cuidar a una persona que se está muriendo, puede representar para las enfermeras una oportunidad para actuar conforme a sus propias concepciones y de esta manera el acto mismo de cuidado al moribundo se convierte en un acto espiritual, una forma en que se acercan a su Dios. A este aspecto se refiere el siguiente fragmento "Yo me metí a estudiar enfermería porque era un cuento con Dios, yo y el servicio a los otros" (Sherazade: 1). 
La buena y la mala espalda: Las enfermeras se clasifican a sí mismas como personas con buena o con mala espalda para la muerte de los pacientes. La buena espalda la tiene la enfermera que posee la facilidad y la voluntad de ayudar a los pacientes que están muriendo. El equipo de trabajo considera que esta persona es quien mejor hace el acompañamiento necesario para los pacientes que están "pegados" para propiciar un tránsito tranquilo y que mueran: "con estos pacientes terminales siento que estoy haciendo lo que siempre quise, me siento útil, ellos mueren y a uno le da tristeza, pero yo siento que por lo menos yo los trataba bien, que pude asesorar a la familia" (Sherazade: 2). Así "la buena espalda" de la enfermera es una ventaja que ella se atribuye sobre otras enfermeras que no la tienen.

La mala espalda, la tiene la enfermera que es considerada por otros y hasta por sí misma, como una persona que de alguna manera, atrae las muertes inesperadas. La enfermera de quien se dice esto, toma el tema con tranquilidad: "[...] es como casual, mire usted" (Aureliano: 3). Un ejemplo se describe en el siguiente diálogo: “—cómo le fue ayer - conociéndolo como es de mala espalda - ¿Cuántos se murieron? - El enfermero se ríe y dice: fueron 3- (Observación: 37). Es de anotar que las enfermeras no son acusadas de los fallecimientos, las personas del hospital no creen que ellos lo causen, solo consideran que lo atraen.

Los fantasmas del hospital: Los participantes reconocen que en muchas unidades hospitalarias existe la creencia en fantasmas, esta se pasa entre las personas que llegan. Es una concepción que persiste sin origen conocido. El personal de enfermería llama a los diferentes ruidos con el nombre de un paciente que murió: "les dije-juraría que en tal habitación estaban bajando las barandas - y ella dijo - mija la espantaron, en esa habitación siempre juegan con las barandas-y fue verdad, yo escuché las barandas" (Celestina: 11).

El fantasma se convierte en una presencia común para todos, ya sea porque lo toman como un juego, porque le temen o porque naturalizan esta presencia que conciben como fantasma: "se aparece la mujer del espejo por corredores o en el ascensor, pero solo aparece después de la media noche" (Observación: 7). Una participante se refirió al fantasma de su unidad, pero solo después de preguntarle al respecto, quizá porque se siente avergonzada. Tal vez por el mismo choque cultural con la academia, representada por la investigadora: "jaja, cómo supo, cuando pasan cosas raras los llamamos por sus nombres; por ejemplo, cuando se nos prende un timbre solo, sobre todo en una habitación específica le decimos Pablito no podemos jugar ahora, Pablito era un niño que murió y nos hacía ir cuando quería jugar, así nos llamaba" ( Pocahontas 2).

\section{Preocupación por el microambiente donde sucede la muerte.}

También reviste un asunto cultural el interés de las enfermeras en el contexto donde ocurre la muerte. Se preocupan que este tenga unas características que en sí mismas tienen significados culturales. Se determinan 
algunas condiciones micro-ambientales específicas. La primera de ellas fue el silencio; para muchas enfermeras es indispensable en los momentos finales de la vida, por ello procuran un silencio adicional al que puede ser común en el hospital e incluye el de los familiares. Este es custodiado celosamente por la enfermera y solo es violado por los diálogos entre ellas, o el del paciente con sus familiares. En el siguiente fragmento, la enfermera expresa su posición respecto al silencio en asocio con el confort: "estar tranquilos, con un ambiente silencioso, sin gente llorando o gritando al lado" (Melibea: 2).

Ellas valoran el silencio como parte de una postura de recogimiento y de respeto hacia la persona que se supone, se encuentra en una de las más importantes transiciones de la vida. Esta decisión parece responder a un imaginario entre las enfermeras e instituciones según el cual, el ambiente ideal para morir es de silencio, y se equipara con la tranquilidad y el confort, sin contar con el significado que tenga el ambiente hospitalario para el paciente o los familiares. El personal de enfermería construye un ideario que los impulsa a crear unas condiciones adecuadas para morir.

Por otro lado, para las enfermeras la muerte es un asunto personal, intimo que solo se puede compartir con aquellas personas más queridas, con quienes compartió diferentes tramos de la vida, para eso, ellas buscan que la muerte no suceda ante los ojos de los otros. Al respecto se refiere la participante: "cierro el cubículo para que sea algo como muy privado y muy intimo" (Julieta: 1).

Incluso a veces las enfermeras prefieren dejar al paciente solo con sus familiares con la creencia que ellos deben realizar sus rituales de despedida sin tener cerca a alguien ajeno a la familia, que pueda interrumpir el flujo del alma del muerto, la despedida y la elaboración del duelo de los familiares, tal como se puede interpretar en los comentarios del participante: "hago que la familia pase o si está en ese proceso dejo que la familia este con él, que si hay 5 hijos, dejo que los 5 hijos estén con él, pero yo no me quedo, yo me voy [...] yo les doy o trato de darles todos los medios para que ellos asuman su duelo" (Joel: 10).

Las sábanas, emergieron como asunto cultural. Según los participantes, aportan a la dignidad y son señal de cuidado e interés. Una sábana limpia, bien doblada y sin arrugas le brinda comodidad y lo mantiene seco, controlando el aumento de la sudoración producto de su inestabilidad hemodinámica, como refiere el fragmento de observación: "cambiemos la sábana que está muy mojadita" (Observación: 37).

La sábana también es un signo cultural asociado a la muerte. Una persona cubierta por completo con una sábana lleva a pensar que puede tratarse de un cadáver. También el estatus de cadáver comienza cuando el rostro del paciente se tapa, en otras palabras, la sábana que cubre la cara, convierte a la persona en cadáver. Aunque no quita el derecho de mantener su dignidad, sí marca físicamente el tránsito hacia la condición de fallecido. En el trabajo de campo se observó que no hay afán por cubrir la cara, solo se cubre el cuerpo con la sábana que tenía si no estaba sucia, o se cambia 
por una limpia: "había ido a ponerle una sábana al paciente fallecido encima de su cuerpo mas no de su cara” (Observación: 33).

\section{Discusión}

La cultura y la religión como expresión de la simbología tienen un papel importante en el proceso de morir. Cada grupo le da un sentido a la muerte y el respeto por las concepciones está relacionado con los cuidados individualizados, integrales y personalizados. Este estudio encontró que las enfermeras lo practican en consonancia con las recomendaciones del Consejo Internacional de Enfermeria: "dispensar cuidados que respeten los derechos humanos y sean sensibles a los valores, costumbres y creencias de todos los pueblos" (14).

Las variadas y complejas concepciones culturales y religiosas, buscan explicar lo inexplicable que es la muerte como parte del destino de los humanos y de un supuesto "después". Gómez sostiene que "desde las más antiguas civilizaciones, las personas se han encargado de darle una explicación a todo aquello que no podían controlar por medio de los mitos" (15). La sensibilidad, respeto y promoción de las concepciones de los otros están incluidos en la "competencia cultural" que, según Marrero (16), es un proceso que incluye la aceptación de las diferencias interculturales para entender la salud y la muerte, además de la capacidad para tratar con sensibilidad cultural y flexibilidad a las diferentes personas del entorno laboral, educativo, social, etc. La capacidad para entender las propias ideas, predisposiciones y reacciones de modo que no violenten las de los pacientes y familiares. También, según Leininger y McFarland, se trata de calidad de cuidado (17).

La relación de la enfermera con el paciente en proceso de morir implica un choque o encuentro de concepciones. Los participantes de este estudio son personas que viven en Medellín, trabajan en instituciones de la ciudad, crecieron en Colombia en diferentes regiones y fueron formadas en universidades del país. No obstante, según, Marrero, "dentro de una misma cultura existen diferencias en cuanto a concepciones" (16). Esto sin tomar en cuenta que la formación universitaria poco contempla las creencias de las enfermeras acerca de la muerte; es decir, se olvida que las enfermeras pueden tener un conocimiento diferente al formal. Adicionalmente, en Colombia en el sistema de cuidados se observa un enfoque biomédico de atención en salud, que riñe con el enfoque integral de cuidado culturalmente competente (18). Un punto que se agrega al choque cultural en el cuidado al final de la vida. Las enfermeras deben hacer el esfuerzo de recordar que su carácter profesional, no lleva a perder su carácter cultural y a considerar la importancia de respetar las concepciones propias de los pacientes y sus familiares, al respecto, Prados y colaboradores, encontraron que los imaginarios sociales tienen gran peso en las emociones y decisiones de las enfermeras respecto a la muerte y los cuidados al final de la vida (19).

Además se evidencian concepciones culturales propias de las enfermeras, como creer que el cuidado de los pacientes en proceso de fallecer y el 
intento por disminuir su sufrimiento son asuntos espirituales en sí mismos, de esta manera se nota como la cultura tiene un papel importante en la toma de decisiones (20). Otras conciben como fantasmas algunas experiencias que viven en zonas del hospital donde suceden más muertes, esto es explicado por Escalante y colaboradores como una expresión de las personas que no elaboran el duelo por la muerte (21). En este caso aún no aceptan la pérdida de un paciente en particular o de los pacientes en general.

También se encontraron creencias en la buena y la mala espalda que tienen ciertas personas para atraer la muerte a manera de energía. Al respeto de lo anterior, Morin plantea que "es la consciencia realista de la muerte lo que suscita el mito: provoca semejante horror que se niega, se desvía y supera en mitos, fantasmas, renace o resucita" (22).

Para las enfermeras, los rituales religiosos y culturales pretenden dar tranquilidad al paciente en la muerte y a los familiares, pues finalmente, estos buscan que él se desapegue y se alcance el descanso del alma de la persona. Otras creen en algo como la figura simbólica del purgatorio que tiene la religión católica; en ese sentido, pueden considerar que la enfermedad y la muerte son formas mediante las cuales la persona limpia sus faltas y queda limpia su alma. El concepto de alma adquiere un papel importante en el cuidado de la persona en proceso de morir, según Nussbaum (23), la palabra "alma" tiene connotaciones religiosas para muchas personas y cada quien puede atenderlas o ignorarlas según lo elija.

Molina (24) por otro lado, encontró que en Colombia es más fácil asumir la muerte como un asunto religioso, pues siguen coexistiendo imaginarios premodernos como estar "sellado" o "pegado", con entornos aparentemente modernos o posmodernos como la ciencia, lo que recuerda el choque cultural que se describió arriba.

El silencio aparece como signo de respeto, ceremonia y de espacio para la reflexión o para la oración; sin embargo, otras culturas no occidentales o americanas, como la mexicana consideran "diferentes rituales con música o risas como una forma de respeto y de ritual” (15). De manera que no es mandatorio, ni debería ser impuesto si el paciente no lo pide, puesto que como dice Gómez "hay reglas, costumbres y rituales para enfrentar la pérdida de un ser querido, que son determinados por la sociedad y que forman parte integral de la ceremonia del duelo" (15) en todo caso, busca que esta transición se dé con la mayor comodidad.

\section{Conclusión}

Las concepciones culturales y espirituales se manifiestan en la práctica diaria de los cuidados al paciente en proceso de morir y significan un interés por su alma, buscan que esta haga su tránsito y "descanse en paz". Constituyen un medio para explicar situaciones misteriosas, como la muerte y el sufrimiento, y para afrontar la pérdida pues dan sentido a las situaciones que se están viviendo.

El cuidado del paciente en proceso de morir representa un choque entre la representación científica de la muerte como asunto biológico heredado de su formación universitaria y su cultura frente a las normas y costumbres 
institucionales. No obstante, en los posibles choques culturales descritos, las enfermeras promueven y respetan las creencias culturales y religiosas de los pacientes y permiten sus expresiones, aunque en ocasiones las juzguen o no las entiendan.

\section{Recomendaciones}

Resaltar el respeto a la individualidad de los pacientes como una característica del cuidado con calidad especialmente en la fase final de la vida. Es importante rescatar el ser cultural de las personas involucradas en el acto del cuidado, no solo del paciente, sino de los familiares y las enfermeras. Las concepciones propias no terminan con la formación universitaria o con la fase de la vida en la cual la persona se encuentre. Sin embargo, se debería entender que es imperativo proteger el derecho de quien está más vulnerable que es el paciente.

Es importante tener en cuenta que la nueva legislación en materia de cuidado al paciente en proceso de fallecer representa importantes retos para las enfermeras, pues obliga a la preparación en el tema y a conocer el contexto no solo legal, sino también social y cultural para que quienes cumplan los protocolos de cuidado al final de la vida, no olviden el carácter multidimensional y complejo de las personas, evitando de esta manera choques culturales y angustia para todos.

\section{Financiación}

Este artículo se desprende de la investigación autofinanciada "Significado de la muerte de los pacientes para las enfermeras" como parte de los requisitos del Doctorado en enfermería de la Universidad de Antioquia. No hubo instituciones patrocinadoras de la investigación.

\section{Conflicto de interés}

Las autoras declaran no tener conflicto de intereses.

\section{Referencias}

1. Geertz C. La interpretación de las culturas.8a ed. Barcelona: Gedisa; 1997.

2. Quijada-González C, Tomás y Garrido GM. Testamento vital: conocer y comprender su sentido y significado. pers.bioét. 18 (2). 138-152. doi: 10.5294/. [Internet] 2014 [citado en 2015 Dic 17] Disponible en: http://www.scielo.org.co/scielo.php?script=sci_arttext\&pid=S012331222014000200004

3. Siles González J, Solano Ruiz M del C. A história cultural do cuidado paliativo em sociedades primitivas: uma revisão integrativa. Rev Esc Enferm USP. [Internet]. 2012 Aug [citado en 2015 Dec 08]; 46(4): 1015-1022. Disponible en: http://www.scielo.br/scielo. php?script $=$ sci_arttext\&pid=S0080-

4. Ariés P; Ranum P. Western attitedes toward death: from the middle age to present.Baltimore: Universidad de Jhon Hopkins; 1974. 
5. Gayol S, Kessler G. La muerte en las ciencias sociales: una aproximación. Pers y Soc 25(21): 51-74. [internet] 2011 [citado en 2015 Dic 17] Disponible en: http://biblioteca.uahurtado.cl/ujah/856/txtcompleto/txta131107.pdf

6. Jimeno M, Varela D, Castillo A. Experiencias de violencia: etnografía y recomposición social en Colombia. Soc. e Cult. 14 (2): 275-285. DOI: 10.5216/sec.v14i2.17604. [Internet], 2011 [citado en 2015 Dic 17]Disponible en: https://revistas.ufg.emnuvens.com.br/fchf/article/ viewFile/17604/10555

7. República de Colombia. Congreso de la República de Colombia. Ley 1733 de 2014. Ley Consuelo Devis Saavedra, mediante la cual se regulan los servicios de cuidados paliativos para el manejo integral de pacientes con enfermedades terminales, crónicas, degenerativas e irreversibles en cualquier fase de la enfermedad de alto impacto en la calidad de vida por la cual se establecen las acciones para la atención integral del cáncer en Colombia. Diario Oficial sin número (8/04/2014).

8. Ministerio de salud y protección social. Resolución 1216 de 2015. Por medio de la cual se da cumplimiento a la orden cuarta de la sentencia T-970 de 2014 de la Honorable corte constitucional en relación con las directrices para la organización con las directrices para la organización y funcionamiento de los comités para hacer efectivo el derecho a morir con dignidad. (20/04/2015).

9. Vega P, González R, Palma C, Ahumada E, Mandiola J, Oyarzún C, et al. Develando el significado del proceso de duelo en enfermeras pediátricas que se enfrentan a la muerte de un paciente a causa del cáncer. Aquichan 2013; 13(1):81-91.

10. Apud Peláez I. Repensar el método etnográfico. Hacia una etnografía multitécnica, reflexiva y abierta al diálogo interdisciplinario. Antipoda; (16): 213-235. [Internet] 2013 [citado en 2015 Oct 27] Disponible en: DOI: http://dx.doi.org/10.7440/antipoda16.2013.10

11. Strauss A, Corbin J. Bases de la investigación cualitativa: técnicas y procedimientos para desarrollar la teoría fundamentada. Medellín: Facultad de enfermería de la Universidad de Antioquia; 2002.

12. Castillo E, Vásquez M. El rigor metodológico en la investigación cualitativa. Colomb Med; 34(3) [internet] 2003[citado en 20 agosto 2014] Disponible en: https://tspace.library.utoronto.ca/bitstream/1807/3460/1/rc03025.pdf

13. Colombia. Ministerio de salud. Resolución 8430 de octubre 4 de 1993, Bogotá [Internet] 1993 [Citado en Octubre 25 de 2015] Disponible en: http://www.minsalud.gov.co/Paginas/Normatividad.aspx

14. Consejo internacional de enfermería CIE. Código deontológico de enfermería. [Internet] 2012 [Citado en sept 16 de 2015] Disponible en: http:// www.icn.ch/images/stories/documents/about/icncode_spanish.pdf

15. Gómez Gutiérrez J. La reacción ante la muerte en la cultura del mexicano actual. Investigación y saberes; 1(1): 39-48 [Internet] 2011 [citado en 20 agosto 2014 Disponible en:

16. http://www.udlondres.com/investigacion_saber_es/pdf/reaccion.pdf 
17. Marrero González CM. Competencia Cultural. Enfoque del modelo de Purnell y Campinha-Bacote en la práctica de los profesionales sanitarios. ENE, Rev Enfermería; Vol 7, No 2 \#ENEvol7n2, 2013 Aug 20 [Internet] 2013 [Citado en 201520 dic] Disponible en: http://ene-enfermeria.org/ojs/index.php/ENE/article/view/278.

18. Leininger M. Culture care diversity and universality: a theory of nursing. New York: National League for nursing; 1991.

19. Reina Leal L.M., Romero Ballén M N. La débil apropiación de la competencia cultural en el cuidado al adulto mayor se expresa en las evidencia científicas. Cul Cuid; ]; 18 (38) [Internet] 2014[citado en 2015 Dic 20 Disponible en: http://dx.doi.org/10.7184/cuid.2014.38.15.

20. Prados-Peña D, Cruz-Quintana F, Muñoz-Vinuesa A, Pappous A, García-Caro M P, et al. Influencia de las emociones en el juicio clinico de los profesionales de la salud a propósito del diagnóstico de enfermedad terminal. Int $\mathrm{J}$ Clin Health Psychol; 10(1): 57-73. [Internet] 2010 [citado en 201509 dic] Disponible en: http://www.redalyc.org/ articulo.oa?id=33712017004.

21. Ignorosa-Navaa CA, González-Juárez L. Cuidados paliativos para una muerte digna. Estudio de un caso. Enferm Universitaria; 11(3):110-116. [Internet] 2014 [acceso 2015 dic 10 ] Disponible en: http://apps.elsevier. es/watermark/ctl_servlet?_f=10\&pident_articulo=90342583\&pident_ usuario $=0 \&$ pcontactid $=\&$ pident_revista $=400 \&$ ty $=34 \&$ accion $=$ L\&orig en $=$ zonadelectura $\& w e b=w w w . e l s e v i e r . e s \& l a n=e s \& f i c h e r o=400 v 11 \mathrm{n} 0$ 3a90342583pdf001.pdf.

22. Escalante H, Orozco Guzmán M, López Peñaloza J, Sigales Ruiz S. Condiciones violentas de duelo y pérdida: un enfoque psicoanalítico. Pensam. Psicol; 12(2): 79-95. [Internet] 2014 [Citado en 2015 dic 10] Disponible en: http://www.scielo.org.co/scielo.php?script=sci_arttext \&pid=S1657-89612014000200006\&lng=en\&tlng=es.

23. Morin E. El método 5: la humanidad de la humanidad, la identidad humana. 2a ed. Madrid: catedra; 2006.

24. Nussbaum M. La crisis silenciosa: Signo y Pensamiento. ISSN 0120-4823

25. [Internet] 2011[Citado en 2013 diciembre 18] Disponible en: <http:// www.redalyc.org/articulo.oa?id=86020038001>

26. Molina Garrido G. Dios como sicario: la muerte violenta y el desorden teológico en Colombia. Rev. Estud. Soc 2015; (51): 241-256 